\title{
STUDY ON ENERGY REGENERATING IN HYBRID ELECTRIC VEHICLE
}

\author{
Zhang Zhisen ${ }^{1,}$, Zeng Qiang ${ }^{2, b}$ \\ ${ }^{1}$ School of Physics and Mechatronic Engineering, Sichuan University of Arts and Science, Sichuan, \\ China \\ ${ }^{2}$ School of Physics and Mechatronic Engineering, Sichuan University of Arts and Science, Sichuan, \\ China \\ athrywood@163.com, b 756739761@qq.com
}

\begin{abstract}
Keywords: energy regenerating, strategy, hybrid electric vehicle
Abstract. A brake energy regenerative strategy was introduced in this paper after the analysis of brake torque distribution and maximum battery charge power within the ECE regulation scope.

Studying on efficiency of regenerating energy under different driving conditions, the models and simulations of the energy regenerating strategy were obtained based on the Mat lab Simulink environment. By considering the comfort of passenger, under the ECE NEDC cycles, a $16 \%$ reclaim of braking regenerative energy was attained.
\end{abstract}

\section{Introduction}

Combined with attempts to improve fuel economy, concerns to reduce polluting emissions created by road vehicles have increased. Over the past few decades, there has been significant development in vehicle engine and body technologies. Thus, it would be more challenging to achieve major gains in fuel economy through modifications of the vehicle engine and body. However, the advent of modern control strategies and the growing environmental concerns associated with vehicles provide new opportunities to enhance fuel economy of vehicles. In particular, an advanced automatic manual transmission (AMT) can offer a greater control of the vehicle [1]. Additionally, the combination of regenerating brake energy and energy management system can enable the vehicle to operate more efficiently over a wider variety of speeds.

HEVs can be roughly classified into the following three categories [2]; 1) Micro hybrid: The typical electric motor power for a sedan micro hybrid is about $2.5 \mathrm{~kW}$ at $12 \mathrm{~V}$; 2) Mild hybrid: The typical electric motor power for a sedan mild hybrid is about $10-20 \mathrm{~kW}$ at $100-200 \mathrm{~V}$; and 3) Full hybrid: The typical electric motor power for a full sedan hybrid is about $50 \mathrm{~kW}$ at $200-300 \mathrm{~V}$. Normally, there is a motor, generator, and engine, adopting series-parallel or complex hybrid architecture. The main advantage of an HEV is that braking regenerative energy can be reclaimed during the process of deceleration. The present micro hybrid vehicles adopt the manual shifts incorporated with the mechanical clutch, which result in lower energy efficiency compared than those equipped with AMT.

An HEV equipped with AMT can be such controlled that according to the characteristics of power system, the motor will work in the optimum efficiency area. Meanwhile, by regenerating the brake kinematic energy, a significant part of the engine brake energy can be reclaimed, which make both the fuel economy and the emission performance more promising. Because of the limited brake force produced by the regenerating period, the anti-lock braking system (ABS) is indispensable for the sake of vehicle safety. To improve fuel economy of hybrid electric vehicles and guarantee the vehicle safety, a brake energy regenerating control strategy is presented in this paper which incorporates the simulation analysis of the efficiency of regenerating energy under ECE NEDC cycles.

\section{Braking Torque Distribution Analysis.}

Figure 1 shows the hybrid arrangement and the regenerative energy flow in an HEV studied in this paper. Under certain braking conditions, the vehicle's kinematic energy can transmitted to the final drive-train, then pass through the AMT, flow into the motor/generator. The motor/generator transform the kinematic energy into electricity, then the electricity can be converted by inverter into direct current and poured into the battery. 
Braking modes analysis. According the braking deceleration, the braking modes can be classified into three categories: intensive braking (deceleration larger than $3 \mathrm{~m} / \mathrm{s}^{2}$ ), moderate braking (deceleration between $1 \mathrm{~m} / \mathrm{s}^{2}$ and $3 \mathrm{~m} / \mathrm{s}^{2}$ ) and mild braking (deceleration less than $1 \mathrm{~m} / \mathrm{s}^{2}$ ). The regenerative energy strategy will be determined by which mode the vehicle is braked. With the intensive braking, the main brake force will be provided by hydraulic force provided by ABS for the sake of the vehicle safety, and the complementary brake force be provided by regenerative motor torque; at the same time the tires slip should be checked to prevent the vehicle from locking the wheel.

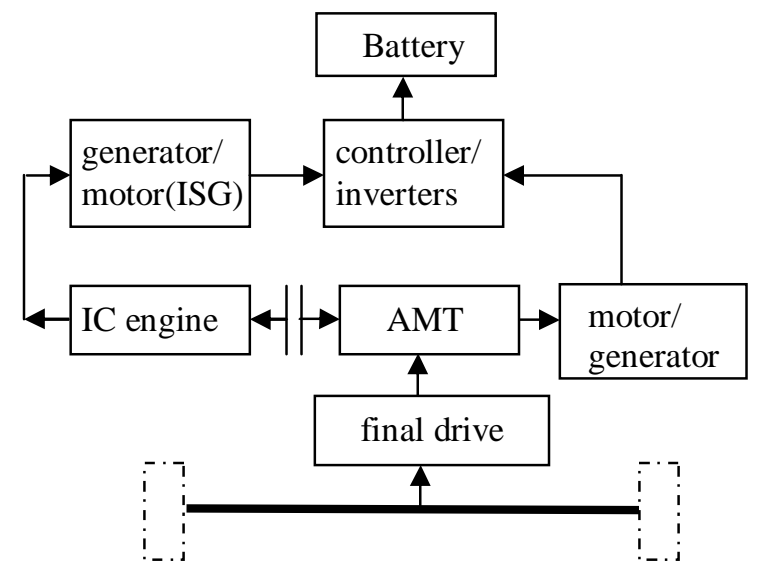

Figure 1 Regenerative braking system scheme
With the moderate braking, the main brake torque will be offered by motor torque and the complementary brake torque is provided by hydraulic system. With the mild braking, all the brake torque can be provided by the motor so as to regenerate more energy. Beside the factor of deceleration, the state of charge (SOC) of battery also has a significant impact on the regenerative process. The hybrid control unit (HCU) will determine the proportions of hydraulic and motor brake torque by the calculation of the battery voltage,current, SOC and motor speed.

Braking strategy of the vehicle. At the beginning of braking, the BCU can evaluate the braking rate of the driver by sensing the pedal position; accordingly, the intensity of the braking (intensive, moderate and mild) was decided, and the required torque was calculated by HCU incorporated with the vehicle speed, battery SOC, motor speed and battery temperature. After that the proportion of $\mathrm{T}_{\text {hyd }}$ and $\mathrm{T}_{\text {mot }}$ can be determined. The preliminary braking strategy was illustrated in figure 2 .

Constraints of regenerative braking. Some constraints should be considered while proposing the regenerative braking strategy. Only if the safety requirement was fully met, the regenerative braking can be accepted. In this paper the ECE regulations was considered. The second one is the working characteristic and the ability of regenerating motor. Figure 3 shows the influence of a typical motor speed on the charging power [4]. The last constraint is the charging safety of the batteries. The appropriate charging interval should be chosen to improve the charging efficiency while avoiding the battery to be overheated.

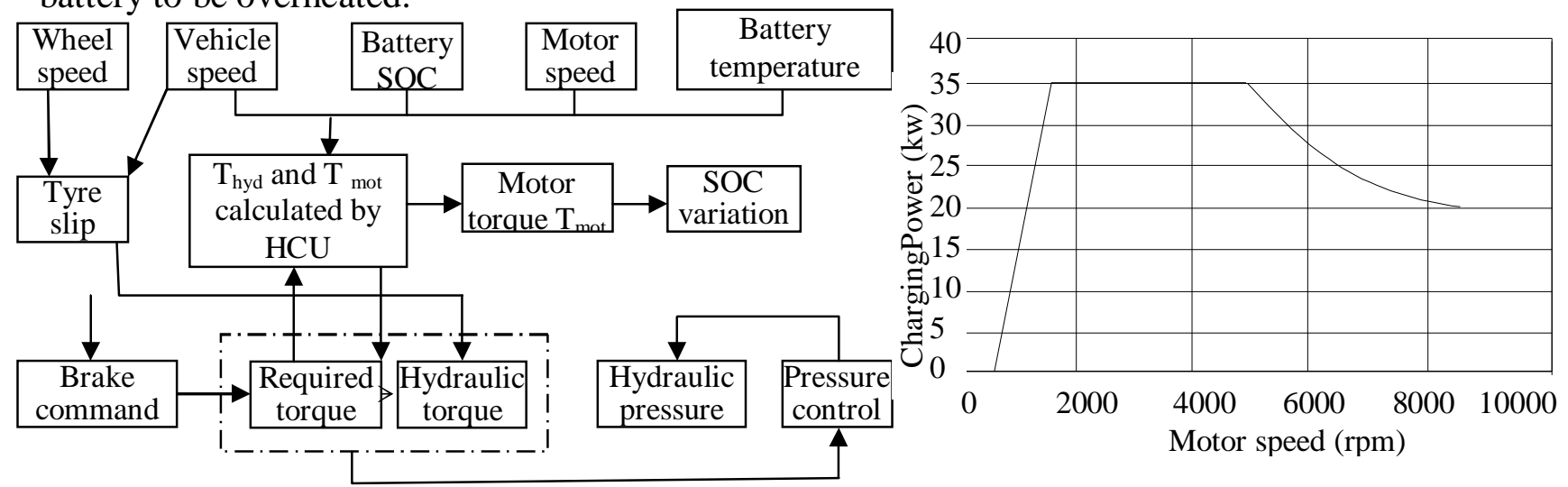

Figure 2 control strategy for regenerative braking

Figure 3 influence of motor speed on charging ower

\section{Brake Torque Distribution and Regenerative Strategies.}

Expected braking rate analysis. Braking torque provided by the wheels can be calculated by the braking force acting on the wheels multiplying the wheel radius. The braking force analysis can be obtained from figure 4 . From the figure, the front and rear wheels normal reaction can be calculated as follows while ignoring wind force $\left(\mathrm{F}_{\mathrm{w}}\right)$ and the inertial torque of the rolling parts [4]. 


$$
\begin{gathered}
F_{z 1}=G\left(b+z h_{g}\right) / L \\
F_{z 2}=G\left(a-z h_{g}\right) / L \\
z=\frac{d u / d t}{g}=\frac{J}{g}
\end{gathered}
$$

Where, $\mathrm{G}$ - gravity of vehicle (N); $\mathrm{a}$, b- distances from gravity center to the front and rear axle accordingly $(m)$; $z$ - braking rate, defined as the quotient of acceleration of the vehicle and the gravity $(g) ; h_{g}-$ vehicle center of gravity height $(\mathrm{m}) ; \mathrm{L}-$ distance between the front and rear axles $(\mathrm{m}) ; \mathrm{u}-$ vehicle speed $(\mathrm{m} / \mathrm{s}) ; \mathrm{t}$ - time(s).

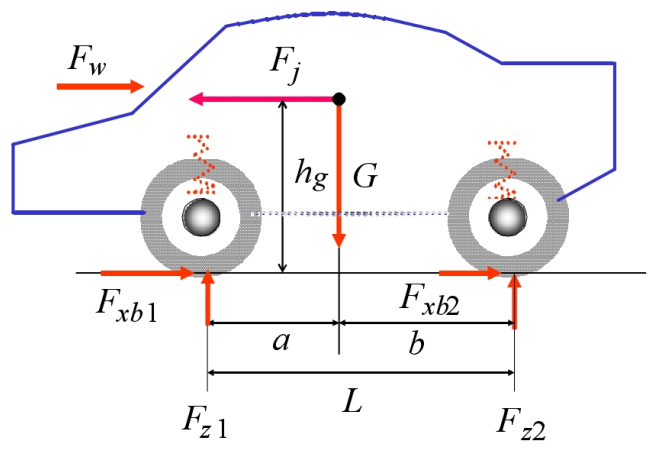

Figure 4 Braking Force Analysis

rear axles were both locked, the formula

$k=z=J / g$ holds, and the braking force can be obtained by formula (4) and (5).

$$
\begin{aligned}
& F_{x b 1}=k F_{z 1}=k G\left(b+k h_{g}\right) / L \\
& F_{x b 2}=k F_{z 2}=k G\left(a-k h_{g}\right) / L \\
& F_{x b 1}+F_{x b 2}=k G
\end{aligned}
$$

The argument values of the above equations of the tested vehicle are listed in table 1 . By employing the values of those parameters, the braking force of front and rear wheels can be plotted under both full laden and no loads conditions respectively (curves in figure 5).By using the above formula, the braking force can be derived under two conditions.

$\begin{aligned} & \text { (i) When front wheels locked } \\ & \text { By formula (4) and (6), Formula }\end{aligned} F_{x b 2}=\frac{L-k h_{g}}{k h_{g}} F_{x b 1}-\frac{b}{h_{g}} G$

(7) holds.

If ${ }^{F_{x b 1}}=0$ then ${ }_{F_{x b 2}}=-\frac{b}{h_{g}} G$ (with no relationship to adhesion utilized (k)); If , $F_{x b 2}=0$

Then $\quad F_{x b 1}=\frac{G b k}{L-k h_{g}}$

The values of $F_{x b 1}$ can be obtained by formula (4) and (8) under different adhesion utilized (equaling to the braking rate of the same values) respectively. Hence, the front wheel brake forces under different conditions could be depicted. The lines was named "f lines group" (see figure 5).

(ii) When rear wheels locked By formula (5) and (6), Formula

$$
F_{x b 2}=\frac{-k h_{g}}{L+k h_{g}} F_{x b 1}+\frac{G a k}{L+k h_{g}}
$$

holds.

Then

If $F_{x b 2}=0$, then $F_{x b 1}=\frac{G a}{h_{g}} \quad$ (with no relationship to adhesion utilized (k); if $F_{x b 1}=0$,

$$
F_{x b 2}=\frac{G a k}{L+k h_{g}}
$$

\begin{tabular}{|c|c|c|c|}
\hline $\begin{array}{l}\text { Vehicle mass } \\
\text { Full laden } \\
\text { /no laden mass }\end{array}$ & $\begin{array}{l}1605 / 1295 \\
(\mathrm{Kg})\end{array}$ & $\mathrm{a} / \mathrm{b} / \mathrm{h}_{\mathrm{g}}$ & $\begin{array}{l}1169 / 1421 / 545 \\
(\mathrm{~mm}) \\
\text { (Full laden) }\end{array}$ \\
\hline \multirow{2}{*}{$\begin{array}{l}\text { Wheel/axle } \\
\text { loads }\end{array}$} & Front axle & \multicolumn{2}{|c|}{$\begin{array}{ll}800 & (\mathrm{~kg}) \text { (no laden }) \\
880 & (\mathrm{~kg})(\text { full laden })\end{array}$} \\
\hline & Rear axle & \multicolumn{2}{|c|}{$\begin{array}{ll}495 & (\mathrm{~kg}) \text { (no laden) } \\
725 & \text { (kg) (full laden) }\end{array}$} \\
\hline
\end{tabular}

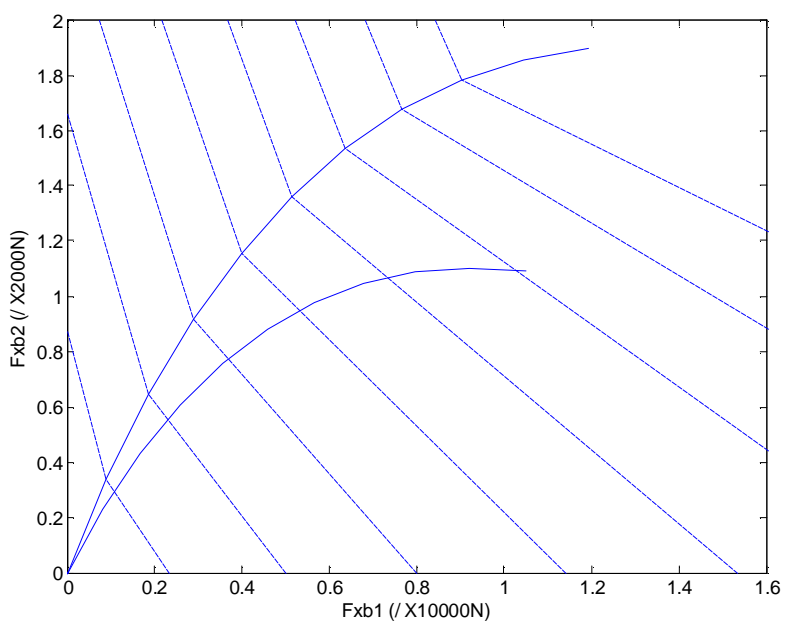

The values of Fxb2 illustrated the rear wheel brake forces can be calculated from formula (5) and (10). The lines named "r lines group" were depicted in figure 5 .

Table 1 tested vehicle parameters (I)

Figure 5 front and rear brake forces (under different $\mathrm{z}$ ) 


\section{Regenerative Strategy and Simulation Requirement of ECE regulations. ECE}

regulation No. 13 - uniform provisions concerning the approval of vehicles of categories $\mathrm{M}, \mathrm{N}$ and $\mathrm{O}$ the approval of vehicles of categories $\mathrm{M}, \mathrm{N}$ and $\mathrm{O}$ with regard to braking required that for all categories of vehicles for $\mathrm{k}$ values between 0.2 and 0.8 [5],

$$
z^{3} 0.1+0.85(k-0.2)
$$

For all states of load of the vehicle, the adhesion utilization curve of the rear axle shall not be

Table 2 tested vehicle parameters (II)

\begin{tabular}{|c|c|}
\hline parameters & values \\
\hline Gear ratios $i_{g}$ & $\begin{array}{lllll}3.400 & 1.955 & 1.272 & 0.954 & 0.740\end{array}$ \\
\hline efficiency & $\begin{array}{lllll}0.96 & 0.96 & 0.97 & 0.98 & 0.98\end{array}$ \\
\hline Final drive ratio $i_{0}$ & 4.166 \\
\hline efficiency & 0.98 \\
\hline Front $\operatorname{area}\left(\mathrm{m}^{2}\right)$ & 2.39 \\
\hline Wheel radius & $304 \mathrm{~mm}$ (static) \\
\hline & $312 \mathrm{~mm}$ (dynamic) \\
\hline Wheel inertia & $1.1859\left(\mathrm{~kg} . \mathrm{m}^{2}\right)$ \\
\hline
\end{tabular}
situated above that for the front axle.

Battery rechargeable power. When the power battery was charged by regenerative electric current, it is necessary to keep the motor regenerating power to be less than battery rechargeable power in order to protect the batteries from damaging. In addition, the inner resistance of the battery is the function of temperature. With the working temperature lowering, the inner resistance will increase dominantly. Under the same temperature, the rechargeable power will drop significantly if the SOC is high, and the inner resistances of battery will increases as well. Though SOC is not preferred to be high while regenerating, SOC should not be kept at very low level because of the battery charge power will be very low when needing to provide acceleration help to the ICE. In this study, the SOC was kept between 0.45 and 0.95 .

Motor regenerative braking. A regenerative motor torque can be calculated as follows.

$$
T_{\text {reg }}=\begin{aligned}
& \text { ì } 9549.3 P_{n} / n_{b}, \\
& \hat{1} 9549.3 P_{n} / n,
\end{aligned} \quad n>n_{b} \quad(12) \quad \text { Where } \mathrm{P}_{\mathrm{n}} \text { is the motor rated power }(\mathrm{kw}), \mathrm{n}_{\mathrm{b}} \text { is the rated }
$$
speed of the motor (rpm). $\mathrm{n}$ is the rotating speed of motor (rpm). The regenerative motor torque can be transmitted to the wheel through drivetrain to produce braking force acting on the vehicle.

$$
F_{x b 1}=\frac{T i_{g} i_{0}}{r h_{T}}
$$

(13) Where $F_{x b 1}$ is the braking force acting on the drive wheel (in this case, the front ones); $i_{g}$ and $i_{0}$ are the transmission ratios of the gear and final drivetrain respectively; $\eta_{T}$ is the efficiency of drivetrain. Table 2 illustrates parameters of the tested vehicle studied in this paper.

AMT strategy while regenerating. Automated Manual Transmission (AMT) was adopted in the tested vehicle in this paper. Due to motor efficiency will change with the motor speed, the AMT controller should make the gearbox shift automatically in order to keep the motor working in the high efficiency area. Figure 6.

\begin{tabular}{|c|c|c|}
\hline Deceleration & \multicolumn{2}{|c|}{ Times start-stop speed $(\mathrm{km} / \mathrm{h})$} \\
\hline 1 & $15-0$ & 55729.1 \\
\hline 2 & $32-0$ & 253629.6 \\
\hline 3 & $50-0$ & 619212.9 \\
\hline 4 & $70-50$ & 148611.1 \\
\hline 5 & $120-0$ & 891666.7 \\
\hline brake energy & \multicolumn{2}{|c|}{$1968849(\mathrm{~J})$} \\
\hline
\end{tabular}

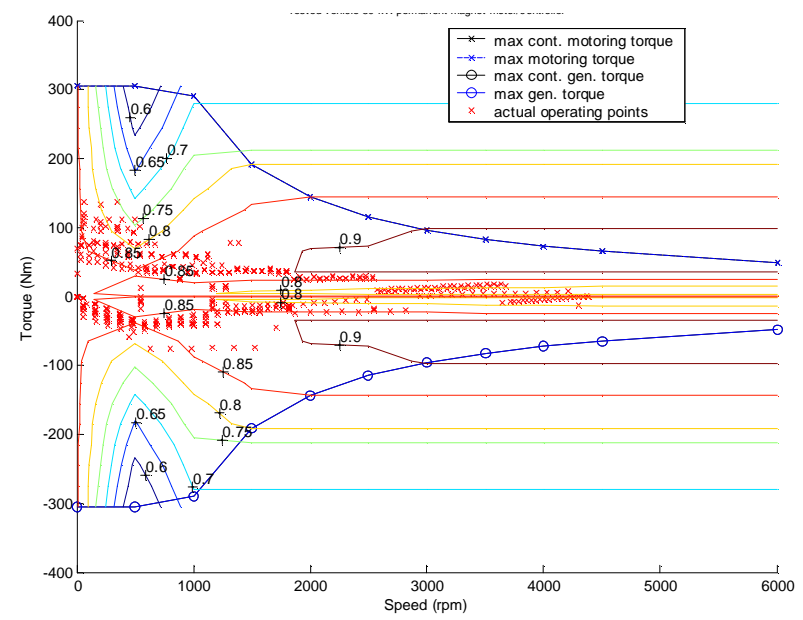

Table 3 braking energy during NEDC cycle (full laden)

Figure6 motor efficiency and actual working points 
Simulation analysis. There are two main simulation methods adopted by analysts nowadays. One is "forward method" while the other is "backward method" [6]. This paper deployed the ADVISOR to carry out the simulation task. The motor efficiency was depicted in figure 6 (red dots). Under the NEDC cycle the vehicle kinetic energy and the regenerative energy can be calculated by following formula respectively.

$$
\begin{aligned}
& \stackrel{\circ}{\mathrm{a}} E_{T}=\stackrel{\mathrm{a}}{\frac{1}{2}} \cdot m \cdot\left(v_{2}^{2}-v_{1}^{2}\right) \\
& \stackrel{\circ}{\mathrm{a}} E_{b a t}=\grave{\mathrm{O}}_{0}^{t}\left(E_{k}-I_{b a t}(t) \times R_{b a t}(t)\right) \times I_{b a t}(t) d t
\end{aligned}
$$

Where $\mathrm{E}_{\mathrm{T}}$ is the vehicle braking kinetic energy which can be reclaimed by regenerative braking $(\mathrm{J}) ; \mathrm{m}$ is the vehicle mass $(\mathrm{kg}) ; \mathrm{v}_{2}$ and $\mathrm{v}_{1}$ are the vehicle end speed and start speed respectively; $\mathrm{E}_{\mathrm{bat}}$ is the battery stored energy $(\mathrm{J}) ; \mathrm{E}_{\mathrm{k}}$ is the electric potential of the battery $(\mathrm{V})$; $\mathrm{I}_{\text {bat }}$ is the recharging current (A); From formula (14), the braking kinetic energy can be calculated as table 3.

From formula (15), the energy reclaimed by regenerative braking can be calculated by ADVISOR while simulating the regenerating process. The total regenerating braking energy was $329191.55 \mathrm{~J}$ which incurred a $16 \%$ reclaim rate during the NEDC cycle. Simulation shows the fuel consumption is $6.1 \mathrm{~L} / 100 \mathrm{~km}$.

\section{Conclusions}

An instance of complex hybrid vehicle architecture was introduced in this paper. The regenerative braking strategy was suggested after the brake torque distribution analysis. Under the constraints of the ECE regulations, battery rechargeable power, motor characteristics and AMT strategy, the simulation was carried out by ADVISOR programs. Simulation results show that the suggested hybrid vehicle has a fuel consumption of $6.1 \mathrm{~L} / 100 \mathrm{~km}$ and a $16 \%$ energy regenerative rate is obtained.

\section{Acknowledgements}

This work was financially supported by the Education Department of Sichuan (No. 15ZA0318) and Sichuan University of Arts and Sciences.

\section{References}

[1] John De Cicco, Feng An, and Marc Ross, Technical Options for Improving the Fuel Economy of U.S. Cars and Light Trucks by 2010-2015, 2001.04.

[2] C. C. Chan, The State of the Art of Electric, Hybrid, and Fuel Cell Vehicles[J](invited paper), Proceedings of the IEEE Vol.95,No.4,April 2007.

[3] Motomu Hakiai, Toshio Taichi, Masahiko Shoda, Takashi Koizumi, Tadashi Ashikaga, Hiroshi Shimizu. Brake system of "Eco-Vehicle"[J]. The 14th International Electric Vehicle Symposium and Exposition, Orlando, USA, 1997.

[4] Yaqing Wang, Daisheng Zhang, Guoqing Shen, optimizing design and simulative calculation of braking force distribution ratio of vehicles[J]. Journal of Hefei University of Technology. 2005. Vol 28. No. 11: 1393-1396(In Chinese).

[5] ECE regulation No. 13-uniform provisions concerning the approval of vehicles of categories M, N and $\mathrm{O}$ with regard to braking. E/ECE/TRANS/505/Rev.1/Add.12/Rev.7, 4 August 2011.

[6] Van Mierlo Joeri et.al. Simulation methodologies for innovative vehicle drive systems, http://etec.vub.ac.be/publications/A71712.pdf 